\title{
The glycosylation of pregnancy-associated glycoproteins and prolactin-related protein-I in bovine binucleate trophoblast giant cells changes before parturition
}

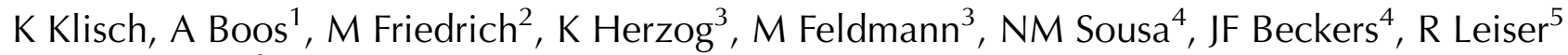 \\ and G Schuler ${ }^{6}$
}

Department of Neuroanatomy, Medical School Hannover, 30625 Hannover, Germany, ${ }^{7}$ Vetsuisse-Faculty, Institute of Veterinary Anatomy, University of Zurich, CH-8057 Zurich, Switzerland, ${ }^{2}$ Institute of Animal Husbandry and Genetics, University of Goettingen, 37075 Goettingen, Germany, ${ }^{3}$ Clinic for Cattle, Hannover Veterinary School, 30173 Hannover, Germany, ${ }^{4}$ Laboratory of Animal Endocrinology and Reproduction, Faculty of Veterinary Medicine, University of Liège, 4000 Liège, Belgium, ${ }^{5}$ Institute of Veterinary Anatomy, Justus Liebig University Giessen, 35392 Giessen, Germany and ${ }^{6}$ Clinic of Veterinary Obstetrics, Gynaecology and Andrology, Justus Liebig University Giessen, 35392 Giessen, Germany

Correspondence should be addressed to K Klisch; Email: klisch.karl@mh-hanover.de

\begin{abstract}
Binucleate trophoblast giant cells (BNC) in the bovine placenta produce glycoproteins, which are delivered into the mother after fusion of BNC with uterine epithelial cells. During most time of pregnancy, BNC produce pregnancy-associated glycoproteins (PAGs) and prolactin-related protein-I (PRP-I) with asparagine-linked lactosamine-type glycans terminating with $\mathbf{N}$-acetyl-galactosamine. We show by lectin histochemistry that terminal $\mathrm{N}$-acetyl-galactosamine (detected by Dolichos biflorus agglutinin, DBA) in placentomal BNC is greatly reduced prior to parturition, while lactosamine-type $\mathbf{N}$-glycans (detected by Phaseolus vulgaris leucoagglutinin, PHA-L) remain unaltered. The change in DBA-staining showed no statistically significant differences between placentomes of cows with and without retention of fetal membranes. Western blots revealed that, at parturition the apparent molecular mass of PAGs and PRP-I is 1-2 kDa lower than in late pregnancy. These changes are due to alterations of asparagine-linked glycans, since the molecular weight of the peptide backbones after enzymatical release of asparagine-linked glycans is identical at late pregnancy and parturition. Lectin western blots showed a reduction of terminal $\mathbf{N}$-acetyl-galactosamine on PAGs at parturition. A lectin sandwich-ELISA was used to differentiate DBA- and PHA-L-binding PAGs in sera of pregnant and non-pregnant cows. The values for DBA-binding PAGs at parturition were not significantly different from non-pregnancy, while the values for PHA-L-binding PAGs were significantly higher at parturition. The peripartal changes of PAG- and PRP-I-glycosylation could alter functional properties of these proteins and might therefore be considered for functional studies. The differentiation of PAG glycoforms in maternal serum could be valuable for a further optimization of PAG-based pregnancy diagnosis in cattle.
\end{abstract}

Reproduction (2006) $132791-798$

\section{Introduction}

Binucleate trophoblast giant cells (BNC) are a characteristic feature of ruminant placenta (Wimsatt 1951, Wooding 1992). The BNC develop from uninucleate trophoblast cells and become binucleate by acytokinetic mitosis (Wimsatt 1951, Wooding 1992, Klisch et al. 1999a). During cell maturation, BNC become polyploid (Klisch et al. 1999b) and large amounts of dense core vesicles accumulate in their cytoplasm. Mature BNC migrate towards the uterine epithelium and fuse with uterine epithelial cells (Wooding 1992). This results in the formation of trinucleate feto-maternal hybrid cells, which release their granules at the basal membrane of the uterine epithelium. Therefore, the BNC facilitate the transport of trophoblast-derived proteins across the otherwise protein-tight synepitheliochorial placental barrier (Wooding \& Flint 1994).

The BNC granules bind some lectins (Phaseolus vulgaris leucoagglutinin, PHA-L; Dolichos biflorus agglutinin, DBA; Vicia villosa agglutinin, VVA) with high specificity (Munson et al. 1989, Jones et al. 1994, Nakano et al. 2002, Klisch \& Leiser 2003). These lectins 
recognize terminal $\mathrm{N}$-acetylgalactosamine (DBA, VVA; Piller et al. 1990) or an oligosaccharide motif in complex asparagine-linked glycans of the lactosamine-type (PHA-L; Hammarström et al. 1982, Green \& Baenziger 1987, Kaneda et al. 2002). It has been demonstrated that in bovine BNC granules, PAGs and PRP-I are the main glycoproteins to which these lectins bind (Klisch \& Leiser 2003, Klisch et al. 2005).

PAGs of ruminants form a large protein family (Green et al. 1998). In cattle, 21 PAG mRNAs have been sequenced (Green et al. 2000), but the number of PAG genes in the bovine and ovine genome has been estimated to be at least 100 (Xie et al. 1997). PAGs belong to the protein family of aspartic proteinases (Xie et al. 1991), but to date no proteolytic activity of ruminant PAGs has been demonstrated. Due to the transfer of PAGs from the trophoblast to the maternal placental stroma and vasculature, the proteins can be detected in the maternal blood during pregnancy and therefore gained importance for pregnancy diagnosis in ruminants (Sasser \& Ruder 1987, Zoli et al. 1992, Green et al. 2005).

PRP-I belongs to a gene family which, like ruminant placental lactogen, arose from the prolactin gene by gene duplication(s; Forsyth \& Wallis 2002). Several different PRP-mRNAs have been identified (Ushizawa et al. 2005), but PRP-I has been demonstrated on the protein level only (Kessler \& Schuler 1997, Klisch et al. 2005). No binding of PRP-I to prolactin or growth hormone receptors has been demonstrated, and to date PRP-I has not been detected in the maternal circulation (Kessler \& Schuler 1997).

In the present study, we demonstrate by lectin histochemistry and lectin western blot that the glycosylation of PAGs and PRP-I in bovine BNC changes before parturition. Similar changes of glycosylation are detected by a lectin-ELISA on PAGs in the serum of late pregnant cows.

\section{Materials and Methods}

\section{Animals}

Placentomal tissue for histochemical procedures was obtained from three groups of cows.

I Midpregnancy placentas $(n=5$; days 95, 110, 115, 170 , and 200) were obtained from a local slaughterhouse. The fetal ages were estimated from the crown-rump length (Schnorr \& Kressin 2001).

II Term placentas $(n=4)$ were obtained from cows undergoing routine cesarean section for fetal/pelvic mismatch after spontaneous onset of birth. Spontaneous onset of birth means spontaneous opening of the cervix, onset of labor, and rupture of fetal membranes after physiological gestational length. The cow was allowed to continue with labor until dystocia became obvious for the respective owner (between 1 and $3 \mathrm{~h}$ after the onset of labor). The cows were then taken to the clinic, where the cesarean sections were performed immediately. No treatment was performed to induce parturition. Placentomes were collected immediately after delivery of the normally developed calves.

III Single placentomes were obtained from 11 cows within $1 \mathrm{~h}$ after spontaneous calving. Whole placentomes were removed from the uterus with an effiminator after Reisinger, modified by Richter (Hauptner, Solingen, Germany), which is a clamping, crushing, and cutting instrument, originally constructed for the removal of ovaries from large animals. This instrument was used to prevent any bleeding from the caruncular stalk into the uterine lumen after removal of a placentome. In the following, the cows were examined for the release of fetal membranes. In six cows, the fetal membranes were released within $12 \mathrm{~h}$ after expulsion of the fetuses (REL) and five animals retained the fetal membranes for more than $12 \mathrm{~h}$ (RET).

For western analysis, placentomal tissue, consisting of unseparated cotyledon and caruncle, was obtained from a local slaughterhouse (day $240, n=1$; day $260, n=2$ ). Similar tissue from three term pregnancies was obtained by cesarean sections at spontaneous birth, which were carried out at the clinic of veterinary obstetrics (University of Giessen, Germany).

Blood samples for the lectin-ELISA were collected at the experimental farm and the clinic for cattle of the veterinary school, Hannover, Germany. Samples were taken from cows at day $210(n=5)$, day $260(n=5)$, partus $(n=7)$, and from non-pregnant cows at least 100 days post partum $(n=10)$. Animal experiments were approved by the competent authorities of Hannover and Giessen districts, and were performed according to the German Law for the protection of Animals (TierschG).

\section{Lectin histochemistry}

The placentomes were immediately cut into slices $(5 \mathrm{~mm}$ thick), which extend from the surface to the base of the placentome. These slices were fixed in $4 \%$ formaldehyde $(\mathrm{v} / \mathrm{v})$ in $0.1 \mathrm{M}$ phosphate buffer $(\mathrm{pH} 7.3)$ for $24 \mathrm{~h}$ and triangular pieces, which include all strata of the placentome, were embedded in paraffin. Sections $(7 \mu \mathrm{m})$ were dewaxed in xylol, rinsed in three changes of ethanol, rehydrated in descending concentrations of ethanol, and rinsed in distilled water. The slides were rinsed in $0.05 \mathrm{M}$ Tris-buffered saline $(\mathrm{pH} 7.6), 1 \mathrm{mM}$ $\mathrm{CaCl}_{2}$ (TBS), and incubated for $45 \mathrm{~min}$ in a humid chamber at $37^{\circ} \mathrm{C}$ with $10 \mu \mathrm{g} / \mathrm{ml}$ biotinylated lectin (DBA; Sigma; PHA-L, EY-Laboratories, San Mateo, CA, USA) in TBS. After washing twice in TBS, the slides were incubated with a preformed streptavidin/biotin-peroxidase (ABC) complex for $60 \mathrm{~min}$ at $37^{\circ} \mathrm{C}$, rinsed in PBS, and 
developed in PBS containing $0.02 \%$ (w/v) diaminobenzidine (DAB), $0.3 \%(\mathrm{w} / \mathrm{v})$ ammonium nickel (III)-sulfate, and $0.015 \%(\mathrm{v} / \mathrm{v}) \mathrm{H}_{2} \mathrm{O}_{2}$.

As controls, the lectins were replaced by TBS or $0.2 \mathrm{M}$ $\mathrm{N}$-acetylgalactosamine (GalNAc) was added to the buffer during incubation with DBA.

\section{Immunohistochemistry}

Sections were dewaxed and rehydrated as described previously. After this, the slides were washed in PBS for $2 \mathrm{~min}$, blocked with $5 \%(\mathrm{w} / \mathrm{v}) \mathrm{BSA}$ in PBS for $30 \mathrm{~min}$ and incubated with polyclonal rabbit antisera in a moist chamber overnight. Anti-PAG (PAG-F4, a gift from Drs J Green and R M Roberts, St Louis, Missouri, USA) was diluted in the ratio of 1:2000 in PBS with 1\% BSA, and anti-bovine PRP-I (Zieler et al. 1990; a gift from Dr L A Schuler, Department of Comparative Biosciences, University of Wisconsin-Madison, Madison, WI, USA) was diluted in the ratio of 1:2000-1:4000 in PBS. Slides were washed twice in PBS and incubated for $30 \mathrm{~min}$ with biotinylated anti-rabbit-lgG (1:100) in PBS. After washing twice in PBS, the slides were incubated with a preformed streptavidin/biotin-peroxidase $(A B C)$ complex, washed in PBS, developed in DAB/ammonium nickel(III) sulfate-solution as above, and coverslipped. In controls, the antisera were replaced by buffer or by diluted $(1: 2000)$ normal Rabbit Immunoglobulin Fraction (DAKO, Hamburg, Germany).

\section{Western analysis}

Slices, expanding from the surface to the base of placentomes, were homogenized in ten volumes Hepes buffer $(0.01 \mathrm{M}$ Hepes and $0.15 \mathrm{M} \mathrm{NaCl})$, homogenates were centrifuged (15000 g; $30 \mathrm{~min})$, and the pellets were discarded. The supernatants were stored at $-80{ }^{\circ} \mathrm{C}$ until analysis. Enzymatical release of $\mathrm{N}$-glycans was performed with PNGase F (New England Biolabs, Frankfurt, Germany) according to the manufacturer's instructions. Briefly, the samples were denaturated in denaturation buffer $\left(100{ }^{\circ} \mathrm{C} ; 10 \mathrm{~min}\right)$ and the recommended quantities of NP-40 and reaction buffer were added. Finally, $500 \mathrm{U}$ PNGase F per $20 \mu \mathrm{g}$ protein were added and the mixture was incubated at $37^{\circ} \mathrm{C}$ for $3 \mathrm{~h}$. In the control samples, reaction buffer was added instead of PNGase F. The samples (10 $\mu$ g protein (Bradford assay)) were separated by SDS-PAGE on $12 \%$ gels and transferred to PVDF membranes. For staining with antisera (anti-PAG-F4; anti-PRP-I), the membranes were blocked with $6 \%(\mathrm{w} / \mathrm{v})$ non-fat-dried milk in PBS and incubated with the antisera (1:1000) in PBS (containing 1\% BSA for the PAG-F4 antiserum) for $1 \mathrm{~h}$. Blots were washed thrice for $10 \mathrm{~min}$ in non-fat-dried milk/PBS, incubated with biotinylated anti-rabbit IgG (1:400) for $45 \mathrm{~min}$, washed and incubated in streptavidin peroxidase for $45 \mathrm{~min}$. Bound antisera were visualized with ECL (ECL Plus Western Blotting Detection Reagents; Amersham Biosciences, Freiburg, Germany). The blots were stripped with Re-Blot Western Blot recycling kit (Chemicon, Schwalbach, Germany) and reused for lectin staining. Therefore, the membranes were blocked with $2 \%$ BSA, $0.5 \%$ Tween 20 in TBS for at least $1 \mathrm{~h}$, incubated with $1 \mu \mathrm{g} / \mathrm{ml}$ lectin (PHA-L; DBA) in TBS for $1 \mathrm{~h}$, washed thrice with TBS, and incubated for $1 \mathrm{~h}$ in $0.05 \mu \mathrm{g} / \mathrm{ml}$ peroxidase-conjugated streptavidin (Dianova, Hamburg, Germany) in TBS. After washing thrice in TBS, the bound lectins were visualized with ECL as described previously.

\section{Lectin-ELISA}

All serum samples were stored at $-20^{\circ} \mathrm{C}$ until analysis. The samples were measured in duplicates and all incubations were carried out at room temperature. One hundred microliters rabbit anti-PAG serum (R727, from the Laboratory of JF Beckers, University of Liège, Liège, Belgium) diluted in the ratio of 1:4000 in PBS were mixed with $100 \mu$ l bovine serum and was incubated on a shaker for $2 \mathrm{~h}$. Biotinylated lectin (0.5 $\mu \mathrm{g}$ PHA-I or DBA in $10 \mu \mathrm{l}$ PBS) was added, incubated for further $2 \mathrm{~h}$, and then the mixture was transferred into a streptavidincoated microtiter plate (BioBind; Thermo, Dreieich, Germany) and incubated overnight on a shaker. After washing thrice with $300 \mu \mathrm{l}$ PBS, $150 \mu \mathrm{l}$ peroxidaselinked anti-rabbit IgG (Amersham Biosciences; 1:2000 in PBS) was added and incubated for $2 \mathrm{~h}$. The wells were washed thrice with PBS, and $100 \mu \mathrm{l}$ ABTS (2-2'-azinodi(3-ethyl benthiazoline sulfonic acid) solution $(0.05 \%$ $(\mathrm{w} / \mathrm{v})$ in $50 \mathrm{mM}$ citric acid $(\mathrm{pH} 4)$ with $0.03 \% \mathrm{H}_{2} \mathrm{O}_{2}$ ) was added. After $30 \mathrm{~min}$, the reaction was stopped with $100 \mu \mathrm{l} 1 \%$ SDS and read on an Elx800 Microplate reader (Biotec, Winooski, Vermont, USA) at $405 \mathrm{~nm}$.

\section{Results}

\section{Lectin and immunohistochemistry}

During midpregnancy (group I), the BNC granules were stained with PAG and PRP-I antisera, and with both lectins (DBA, PHA-L; Fig. 1). In addition, the PRP-I antiserum showed a moderate staining of the maternal stroma in all the three groups. In the term placentas (group II), both antisera bound to BNC, which were reduced in number. All remaining $B N C$ at this stage of pregnancy stained with PHA-L, but DBA-positive BNC were reduced considerably and completely absent occasionally (Fig. 1). In some cases, the DBA-positive BNC were clustered in fetal villi, which were surrounded by the otherwise negative tissue (Fig. 2). Controls were consistently negative (Fig. 3).

In group III, the number of lectin-stained BNC was counted in ten microscopical fields of vision (each 


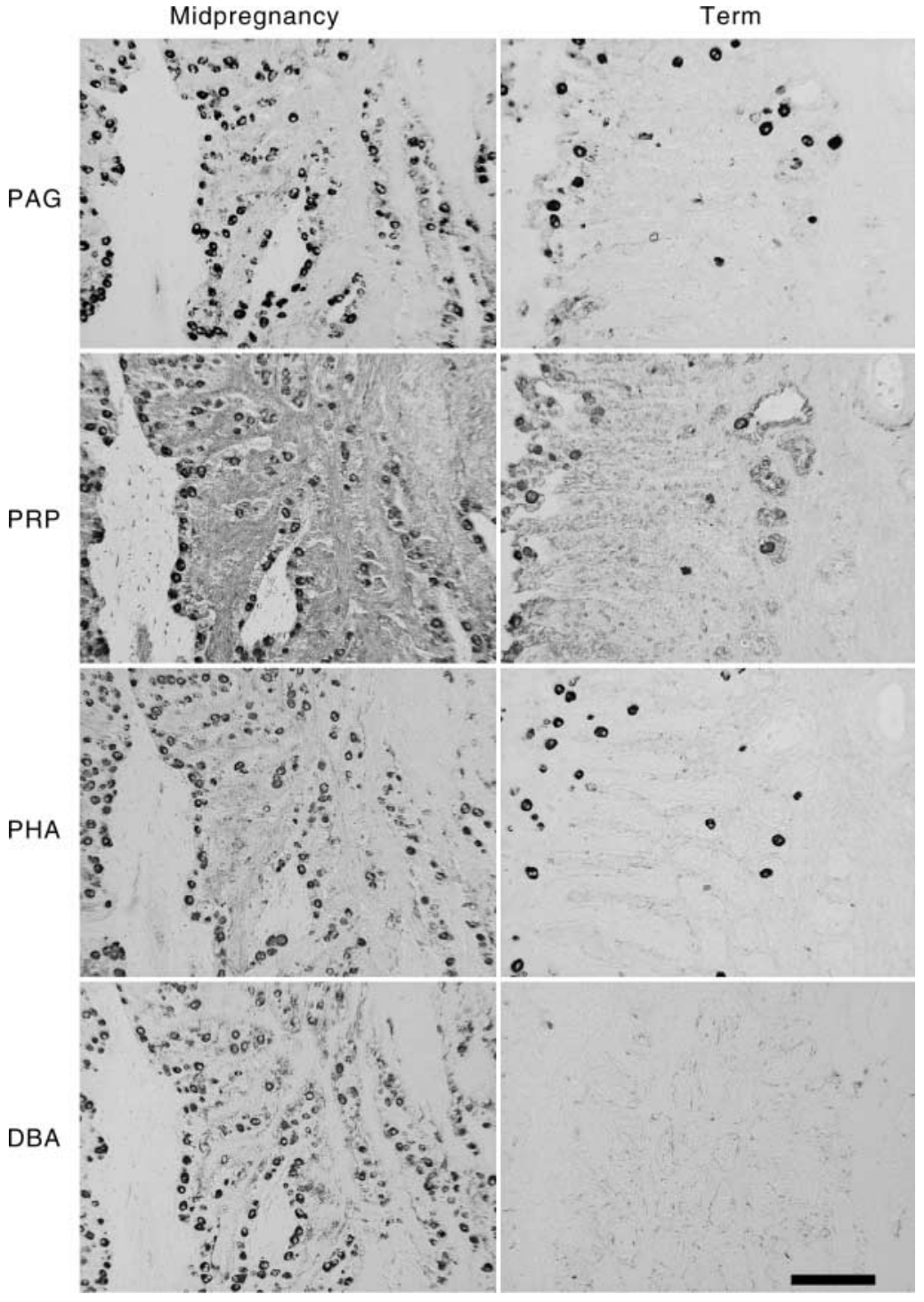

Figure 1 Representative serial sections of midpregnant (day 180) and term placentomes. BNC are stained with the antisera (PAG, PRP-I) and PHA-L lectin. DBA binds to the $\mathrm{BNC}$ at midpregnancy, but the specific staining is absent at term. Scale bar represents $200 \mu \mathrm{m}$. $\left.0.75 \mathrm{~mm}^{2}\right)$. There was no significant difference (Mann-Whitney rank sum test) between animals with retention of fetal membranes (RET) and those which released fetal membranes within $12 \mathrm{~h}$ post partum (REL; Fig. 4).

\section{Western analysis}

In the late pregnancy samples, the major glycosylated PAG isoform had an estimated molecular weight (MW) of approximately $66 \mathrm{kDa}$, with minor isoforms at 56 and $75 \mathrm{kDa}$ (Fig. 5A). The MW of PAGs was reduced to

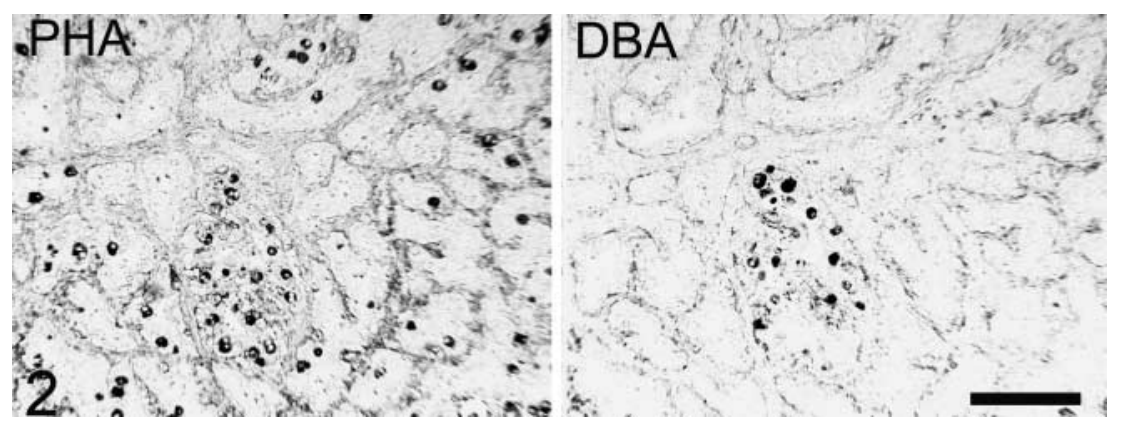

Figure 2 In term placenta, PHA-L binds to several BNC which are diffusely distributed. DBA binds only to a subpopulation of BNC, which are located with a high cell density in a single fetal villus. Scale bar represents $200 \mu \mathrm{m}$. 


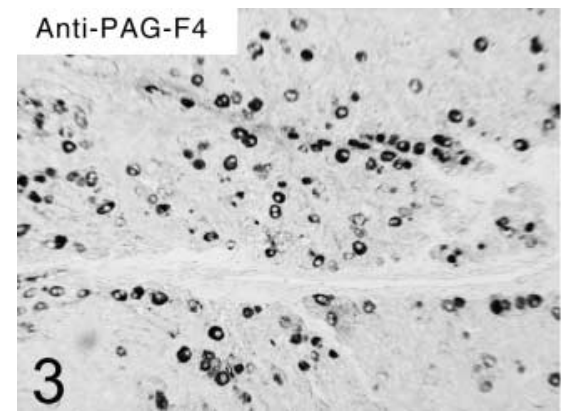

Normal rabbit Ig
$37 \mathrm{kDa}$ by PNGase-F treatment. In the term samples, the expression of PAGs was strongly reduced and the main band was observed at $64 \mathrm{kDa}$.

The expression of PRP did not change obviously between late pregnancy and term, but the glycosylated form in late pregnancy showed a slightly higher apparent MW (36 kDa), compared with term (35 kDa; Fig. 5B). The antiserum also bound to glycoproteins of $44 \mathrm{kDa}$ (late pregnancy) or $42.5 \mathrm{kDa}$ (term).

In late pregnancy, PHA binds to the three bands of PAG $(75,66$, and $56 \mathrm{kDa})$, to PRP (36 kDa), and to the $44 \mathrm{kDa}$ glycoprotein (Fig. 5C). At term, the binding to the $44 \mathrm{kDa}$ glycoprotein and PRP remains relatively strong. In term placenta samples, faint bands at $64 \mathrm{kDa}$ can be seen.

The binding of DBA to PAGs in late pregnancy is clearly visible, but, compared with PHA-L, the binding to PRP is much less intensive (Fig. 5D). At term, no binding to PAG or PRP can be observed. There is only binding to two non$\mathrm{N}$-glycosylated proteins of 75 and > $100 \mathrm{kDa}$.

\section{Lectin-ELISA}

When biotinylated PHA-L was used to immobilize PAGs on the streptavidin-coated microtiter plates, the measured optical densities (OD) of non-pregnant cows (OD 0.20; \pm 0.016$)$ were significantly lower $(P<0.05$; Dunn's multiple comparison test) than day 210 (1.55; $\pm 0.49)$, day $260(1.30 ; \pm 0.55)$, and term samples (1.36; \pm 0.48 ; Fig. 6A).

The OD values for DBA-binding PAG (Fig. 6B) tended to decrease steadily between day $210(1.93 ; \pm 0.92)$, day $260(1.05 ; \pm 0.92)$, and term $(0.59 ; \pm 0.46)$, but differences were not significant $(P>0.05)$. Term and nonpregnant samples $(0.32 ; \pm 0.04)$ did not differ significantly, while the latter were significantly lower than values obtained at 210 and 260 days $(P<0.05)$.

\section{Discussion}

Glycosylation is a major post-translational modification of proteins, which influences several protein characteristics like receptor binding, intracellular sorting, and resistance to enzymatical degradation (Gabius et al. 2004, Sinclair \& Elliott 2005). The glycosylation machinery of ruminant BNC attaches unusual glycans to their major secretory proteins. The glycosylation pattern has been investigated in several lectin histochemical studies (Munson et al. 1989, Lehmann et al. 1992, Jones et al. 1994, Nakano et al. 2002, Klisch \& Leiser 2003). The binding of PHA-L indicates the presence of $\mathrm{N}$-acetyllactosamine-type glycans (Hammarström et al. 1982, Green \& Baenziger 1987, Kaneda et al. 2002). This kind of glycosylation appears to be conserved within the bovids, since PHA-L also binds to granules of ovine (Jones et al. 1994) and water buffalo (Carvalho et al. 2006) BNC. In sheep, it has been demonstrated that PHA binds to PAG, which was immunopurified with the SBU-3 antibody (Atkinson et al. 1993). The present study shows that in cattle the PHA-L-binding epitope is constantly expressed around parturition, since $\mathrm{BNC}$ at parturition are still stained with PHA-L. The present results of the western analysis confirm earlier findings that PHA-L binds to PAGs and PRP-I (Klisch \& Leiser 2003).

A specific feature is the binding of DBA to BNC granules, which occurs in early pregnancy between days 29 and 40 (Lehmann et al. 1992) and continues close to term (day 270; Jones et al. 1994). Recently, it was shown that GalNAc is part of $\mathrm{N}$-glycans of bovine PAGs and

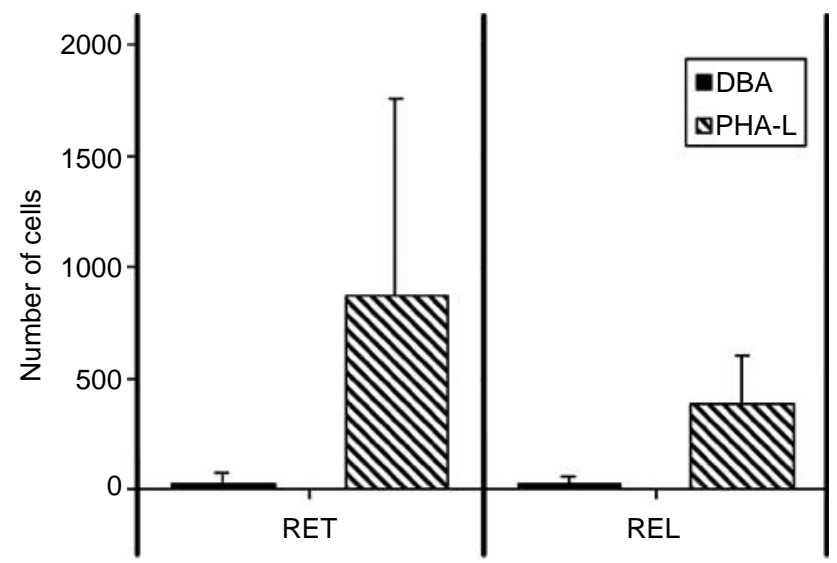

Figure 4 Number of DBA and PHA-L positive cells in ten microscopical fields (each $0.75 \mathrm{~mm}^{2}$ ). Data are expressed as mean \pm s.D. No significant difference between animals with a retention of fetal membranes (RET, $n=5)$ and those which released fetal membranes within $12 \mathrm{~h}$ (REL, $n=6$ ) were observed. 
PRP-I (Klisch \& Leiser 2003, Klisch et al. 2005). The strongly reduced binding of DBA to BNC in the term placenta demonstrates the absence of terminal GalNAC in BNC at parturition. One explanation for the absence of lectin binding could be that GalNac is masked by the addition of other molecules to the glycans. For example, the addition of sulfate to GalNAc inhibits the binding of VVA (Green et al. 1987). A second

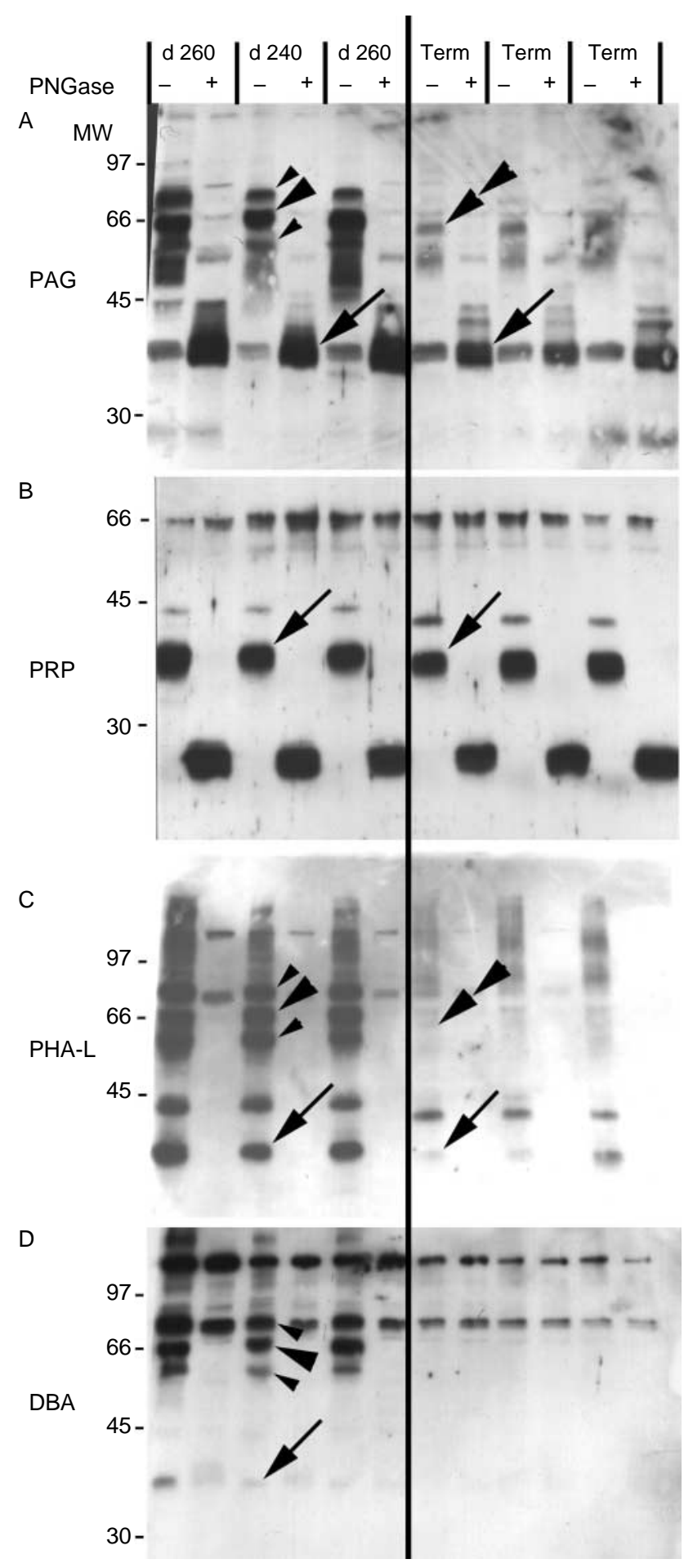

explanation could be that no GalNAc is attached to $\mathrm{N}$-glycans around parturition. The latter possibility appears more likely, since the reduced $\mathrm{MW}$ of periparturent PAGs (and PRP-I) could simply result from the absence of GalNAc. Possibly, the GalNActransferase, which adds GalNAc to glycans on PAGs, could be regulated by the prepartal shift in placental steroidogenesis from the predominant production of progesterone and biologically inactive conjugated estrogens to active free estrogens (Schuler et al. 1994, Hoffmann et al. 1997). A downregulation by estrogens has been described for the glycohormone GalNActransferase (Dharmesh \& Baenziger 1993).

The highly specific glycosylation pattern of BNCderived secretory proteins suggests that the glycans might have specific functions. The specific glycosylation of PAGs might be important for immunoregulatory functions during pregnancy. Recently, it was shown that PAGs produced by BNC are deposited in the stromal layer of the caruncles (Wooding et al. 2005). At this location, PAG-glycans might interact with selectins, and could thereby inhibit selectin-mediated cell adhesion. This could be important for the absence of leucocytes in the bovine placentomal tissue (Lee et al. 1997). The role of the observed changes of glycosylation is still completely obscure, but the fact that there are changes should be considered for functional studies in the future.

In the maternal circulation, PAGs have an outstanding long half-life, which varies between different stages of pregnancy and also depends on the test systems applied. In early pregnancy (after induced late embryonic death at days 30-38), the PAG-1 half-life is 3-4 days (Szenci et al. 2003). A postpartal half-life of 8.4 days was observed by Sasser \& Ruder (1987) and Kiracofe et al. (1993). Such a long half-life limits the applicability of PAG-based pregnancy testing if cows are tested within 100 days after parturition for a new pregnancy. Recently, a new ELISA was established (Green et al. 2005), which

Figure 5 ((A)-(D)) Western blot of placentomal tissue of three late pregnant (days 240 and 260) and three term placenta (10 $\mu \mathrm{g} /$ lane). Samples without $(-)$ or with $(+)$ enzymatical release of asparaginelinked glycans were loaded. (A) PAG. Blots were probed with anti-PAG serum (PAG-F4). In late pregnancy, the main PAG isoform has an approximate MW of $66 \mathrm{kDa}$ (big arrowhead) and minor band can be seen at 75 and $56 \mathrm{kDa}$ (small arrowheads). At term, a $64 \mathrm{kDa}$ band (double arrowheads) was the most prominent. The deglycosylated PAG had a MW of $37 \mathrm{kDa}$ (arrows). (B) PRP-I. Main PRP-I bands at late pregnancy and term were at 35 and $34 \mathrm{kDa}$ respectively, and were reduced to $25 \mathrm{kDa}$ after deglycosylation. (C) PHA-L. In late pregnancy, PHA-L binds to PAGs (compare with (A)) with a main band at $66 \mathrm{kDa}$ (big arrowhead; see also Fig. 4A) and minor bands at 75 and $56 \mathrm{kDa}$ (small arrowheads). There is also binding to PRP-I (arrows, see Fig. 4B) and to a $44 \mathrm{kDa}$ glycoprotein, which reacts with the PRP-I antiserum. At term, faint bands (double arrowheads) are seen in the same region $(64 \mathrm{kDa})$ as in (A). (D) DBA. DBA binds to PAGs in the late pregnancy samples (arrowhead marks the 75, 66, and 56 kDa PAG), but not in term placentas. PRP-I is seen as faint band in the late pregnancy samples (arrow). 

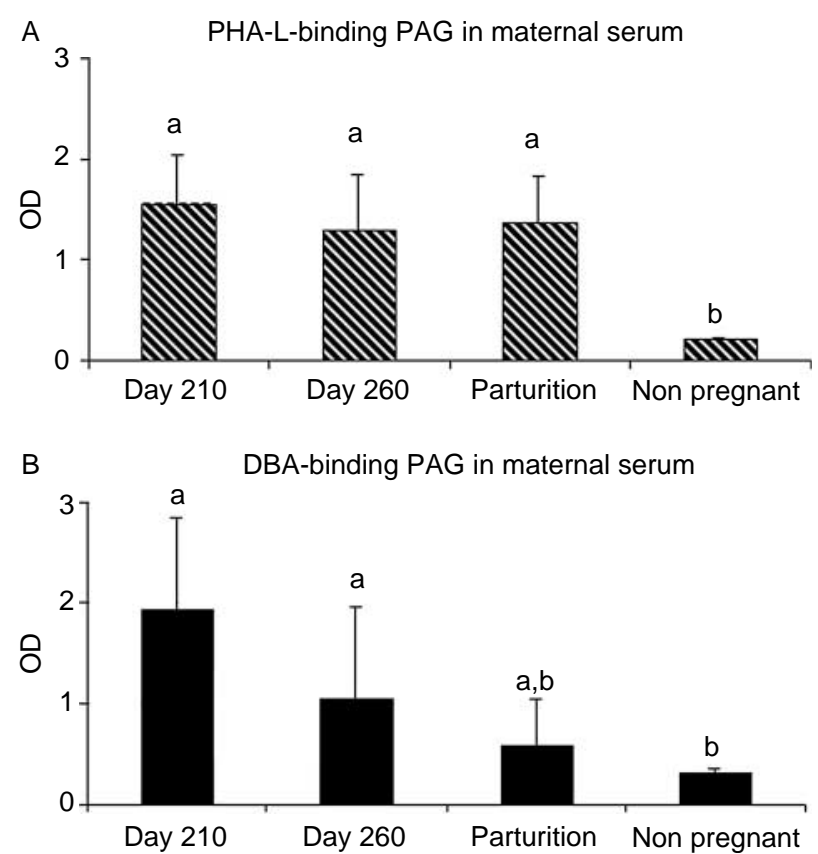

Figure 6 (A) PHA-L-ELISA with sera of pregnant and no-pregnant cows. The mean OD values are expressed (+S.D.). Different superscripts denote statistically different values $(P<0.05)$. (B) DBA-ELISA with sera of pregnant and non-pregnant cows. The mean OD values are expressed (+S.D.). Different superscripts denote statistically different values $(P<0.05)$

overcomes this problem, since it detects PAGs, which have a shorter serum half-life (4.3 days). Protein glycosylation is one important factor, which regulates the half-life of serum proteins. For example, the sulfated GalNAc in lutropin is responsible for its rapid clearance, which is a prerequisite for the pulsatory changes of lutropin concentration (Mi et al. 2002). Glycans with terminal GalNAc are potential ligands for the asialoglycoprotein receptor (Coombs et al. 2006), which is important for the clearance of asialoglycoproteins from blood. Therefore, the longer postpartal serum half-life of PAGs and perhaps also the dramatic prepartal increase in PAG serum concentration (Sasser \& Ruder 1987, Green et al. 2005) might be caused by the peripartal loss of terminal GalNAc.

The values of the PHA-L-ELISA at parturition were at the same level as at late pregnancy. This does not correlate to the obvious partal decrease in the placental PAGexpression, which is revealed by the reduced number of partal BNC and the paleness of PAG-bands in western-blot analysis of partal samples. The explanation for this discrepancy could be that the high partal PHA-L-ELISAvalues reflect PAGs, which were released into the maternal blood at relatively high rates before parturition, while the histochemical and western analyses show the low quantities, which remain in the placenta. One astonishing finding is that, in contrast to other test systems, no peripartal peak of PAG-concentration is seen in the
PHA-L-ELISA. Possibly, the PHA-L-ELISA recognizes only a subpopulation of PAGs, which has a serum profile different from PAGs, detected by other test systems. Such differences could be advantageous for an application in pregnancy testing.

Our data demonstrate a substantial peripartal switch of glycosylation of secretory glycoproteins that are produced by the BNC in the bovine placenta. On these proteins, terminal GalNAc on asparagine-linked glycans disappears prior to parturition. A similar trend with reduced partal quantities of DBA-binding PAGs in maternal serum was revealed by the lectin-ELISA. The functional background of this change is still obscure, but a modulation of receptor binding or regulation of serum half-life appears possible.

\section{Acknowledgements}

The authors thank Silke Fischer for excellent technical assistance, Drs J Green and R M Roberts, College of Veterinary Medicine, University of Missouri St Louis, MO, USA for the donation of the PAG-F4 antiserum, Dr L A Schuler, Department of Comparative Biosciences, University of Wisconsin-Madison, Madison, WI, USA for the anti-PRP-I serum and the German Research Foundation (DFG) for financial support (grant KI 1835/1). The authors declare that there is no conflict of interest that would prejudice the impartiality of this scientific work.

\section{References}

Atkinson YH, Gogolin-Ewens KJ, Hounsell EF, Davies MJ, Brandon MR \& Seamark RF 1993 Characterization of placentation-specific binucleate cell glycoproteins possessing a novel carbohydrate. Evidence for a new family of pregnancy-associated molecules. Journal of Biological Chemistry 268 26679-26685.

Carvalho AF, Klisch K, Miglino MA, Pereira FT \& Bevilacqua E 2006 Binucleate trophoblast giant cells in the water buffalo (Bubalus bubalis) placenta. Journal of Morphology 267 50-56.

Coombs PJ, Taylor ME \& Drickamer K 2006 Two categories of mammalian galactose-binding receptors distinguished by glycan array profiling. Glycobiology 16 1C-7C.

Dharmesh SM \& Baenziger JU 1993 Estrogen modulates expression of the glycosyltransferases that synthesize sulfated oligosaccharides on lutropin. PNAS 90 11127-11131.

Forsyth IA \& Wallis M 2002 Growth hormone and prolactin-molecular and functional evolution. Journal of Mammary Gland Biology and Neoplasia 7 291-312.

Gabius HJ, Siebert HC, Andre S, Jimenez-Barbero J \& Rudiger H 2004 Chemical biology of the sugar code. Chembiochem 5 740-764.

Green ED \& Baenziger JU 1987 Oligosaccharide specificities of Phaseolus vulgaris leukoagglutinating and erythroagglutinating phytohemagglutinins. Interactions with $\mathrm{N}$-glycanase-released oligosaccharides. Journal of Biological Chemistry 262 12018-12029.

Green ED, Brodbeck RM \& Baenziger JU 1987 Lectin affinity highperformance liquid chromatography: interactions of $\mathrm{N}$-glycanasereleased oligosaccharides with leukoagglutinating phytohemagglutinin, concanavalin A, Datura stramonium agglutinin, and Vicia villosa agglutinin. Analytical Biochemistry 167 62-75.

Green JA, Xie S \& Roberts RM 1998 Pepsin-related molecules secreted by trophoblast. Reviews of Reproduction 3 62-69. 
Green JA, Xie S, Quan X, Bao B, Gan X, Mathialagan N, Beckers JF \& Roberts RM 2000 Pregnancy-associated bovine and ovine glycoproteins exhibit spatially and temporally distinct expression patterns during pregnancy. Biology of Reproduction 62 1624-1631.

Green JA, Parks TE, Avalle MP, Telugu BP, McLain AL, Peterson AJ, McMillan W, Mathialagan N, Hook RR, Xie S \& Roberts RM 2005 The establishment of an ELISA for the detection of pregnancyassociated glycoproteins (PAGs) in the serum of pregnant cows and heifers. Theriogenology 63 1481-1503.

Hammarström S, Hammarström ML, Sundblad G, Arnarp J \& Lonngren J 1982 Mitogenic leukoagglutinin from Phaseolus vulgaris binds to a pentasaccharide unit in $\mathrm{N}$-acetyllactosamine-type glycoprotein glycans. PNAS 79 1611-1615.

Hoffmann B, Goes de Pinho T \& Schuler G 1997 Determination of free and conjugated oestrogens in peripheral blood plasma, feces and urine of cattle throughout pregnancy. Experimental and Clinical Endocrinology \& Diabetes 105 296-303.

Jones CJ, Koob B, Stoddart RW, Hoffmann B \& Leiser R 1994 Lectinhistochemical analysis of glycans in ovine and bovine near-term placental binucleate cells. Cell and Tissue Research 278 601-610.

Kaneda Y, Whittier RF, Yamanaka H, Carredano E, Gotoh M, Sota H, Hasegawa Y \& Shinohara Y 2002 The high specificities of Phaseolus vulgaris erythro- and leukoagglutinating lectins for bisecting GlcNAc or beta 1-6-linked branch structures, respectively, are attributable to loop B. Journal of Biological Chemistry 277 16928-16935.

Kessler MA \& Schuler LA 1997 Purification and properties of placental prolactin-related protein-I. Placenta 18 29-36.

Kiracofe GH, Wright JM, Schalles RR, Ruder CA, Parish S \& Sasser RG 1993 Pregnancy-specific protein B in serum of post partum beef cows. Journal of Animal Science 71 2199-2205.

Klisch K \& Leiser R 2003 In bovine binucleate trophoblast giant cells, pregnancy-associated glycoproteins and placental prolactin-related protein-I are conjugated to asparagine-linked $\mathrm{N}$-acetylgalactosaminyl glycans. Histochemistry and Cell Biology 119 211-217.

Klisch K, Pfarrer C, Schuler G, Hoffmann B \& Leiser R 1999a Tripolar acytokinetic mitosis and formation of feto-maternal syncytia in the bovine placentome: different modes of the generation of multinuclear cells. Anatomy and Embryology 200 229-237.

Klisch K, Hecht W, Pfarrer C, Schuler G, Hoffmann B \& Leiser R 1999b DNA content and ploidy level of bovine placentomal trophoblast giant cells. Placenta 20 451-458.

Klisch K, De Sousa NM, Beckers JF, Leiser R \& Pich A 2005 Pregnancy associated glycoprotein- $1,-6,-7$, and -17 are major products of bovine binucleate trophoblast giant cells at midpregnancy. Molecular Reproduction and Development 71 453-460.

Lee CS, Wooding FB \& Morgan G 1997 Quantitative analysis throughout pregnancy of intraepithelial large granular and non-granular lymphocyte distributions in the synepitheliochorial placenta of the cow. Placenta 18 675-681.

Lehmann M, Russe I \& Sinowatz F 1992 Detection of lectin binding sites in the trophoblast of cattle during early pregnancy. Anatomia, Histologia, Embryologia 21 263-270.

Mi Y, Shapiro SD \& Baenziger JU 2002 Regulation of lutropin circulatory half-life by the mannose/ $\mathrm{N}$-acetylgalactosamine-4-SO4 receptor is critical for implantation in vivo. Journal of Clinical Investigation 109 269-276.

Munson L, Kao JJ \& Schlafer DH 1989 Characterization of glycoconjugates in the bovine endometrium and chorion by lectin histochemistry. Journal of Reproduction and Fertility 87 509-517.
Nakano H, Shimada A, Imai K, Takahashi T \& Hashizume K 2002 Association of Dolichos biflorus lectin binding with full differentiation of bovine trophoblast cells. Reproduction 124 581-592.

Piller V, Piller F \& Cartron JP 1990 Comparison of the carbohydratebinding specificities of seven $\mathrm{N}$-acetyl-D-galactosamine-recognizing lectins. European Journal of Biochemistry 191 461-466.

Sasser RG \& Ruder CA 1987 Detection of early pregnancy in domestic ruminants. Journal of Reproduction and Fertility Supplement 34 261-271.

Schnorr B \& Kressin M 2001 Altersbestimmung der Frucht. In Embryologie der Haustiere, edn 5, pp 64-65. Eds B Schnorr \& M Kressin. Stuttgart: Enke Verlag.

Schuler G, Hartung F \& Hoffmann B 1994 Investigations on the use of C-21-steroids as precursors for placental oestrogen synthesis in the cow. Experimental and Clinical Endocrinology 102 169-174.

Sinclair AM \& Elliott S 2005 Glycoengineering: the effect of glycosylation on the properties of therapeutic proteins. Journal of Pharmaceutical Sciences 94 1626-1635.

Szenci O, Beckers JF, Sulon J, Bevers MM, Borzsonyi L, Fodor L, Kovacs F \& Taverne MA 2003 Effect of induction of late embryonic mortality on plasma profiles of pregnancy associated glycoprotein 1 in heifers. Veterinary Journal 165 307-313.

Ushizawa K, Takahashi T, Hosoe M, Kaneyama K \& Hashizume K 2005 Cloning and expression of two new prolactin-related proteins, prolactin-related protein-VIII and -IX, in bovine placenta. Reproductive Biology and Endocrinology 368.

Wimsatt WA 1951 Observations on the morphogenesis, cytochemistry, and significance of the bin cleate giant cells of the placenta of ruminants. American Journal of Anatomy 89 233-281.

Wooding FB 1992 Current topic: the synepitheliochorial placenta of ruminants: binucleate cell fusions and hormone production. Placenta 13 101-113.

Wooding FBP \& Flint APF 1994 Placentation. In Marshall's Physiology of Reproduction, edn 4, pp 233-460. Ed. GE Lamming. London: Chapman \& Hall.

Wooding FB, Roberts RM \& Green JA 2005 Light and electron microscope immunocytochemical studies of the distribution of pregnancy associated glycoproteins (PAGs) throughout pregnancy in the cow: possible functional implications. Placenta 26 807-827.

Xie SC, Low BG, Nagel RJ, Kramer KK, Anthony RV, Zoli AP, Beckers JF \& Roberts RM 1991 Identification of the major pregnancy-specific antigens of cattle and sheep as inactive members of the aspartic proteinase family. PNAS $\mathbf{8 8}$ 10247-10251.

Xie S, Green J, Bixby JB, Szafranska B, DeMartini JC, Hecht S \& Roberts RM 1997 The diversity and evolutionary relationships of the pregnancy-associated glycoproteins, an aspartic proteinase subfamily consisting of many trophoblast-expressed genes. PNAS 94 12809-12816.

Zieler CG, Kessler MA \& Schuler LA 1990 Characterization of a novel prolactin-related protein from bovine fetal placenta. Endocrinology 126 2377-2382.

Zoli AP, Guilbault LA, Delahaut P, Ortiz WB \& Beckers JF 1992 Radioimmunoassay of a bovine pregnancy-associated glycoprotein in serum: its application for pregnancy diagnosis. Biology of Reproduction 46 83-92.

Received 23 May 2006

First decision 26 June 2006

Accepted 27 August 2006 